\title{
Preface
}

\section{To be the best in marine sciences*}

\author{
SUN Song ${ }^{* *}$, WANG Fan \\ Institute of Oceanology, Chinese Academy of Sciences, Qingdao 266071, China \\ Received Jun. 14, 2020; accepted for publication Jun. 25, 2020 \\ (C) Chinese Society for Oceanology and Limnology, Science Press and Springer-Verlag GmbH Germany, part of Springer Nature 2020
}

\begin{abstract}
Every institute in the world has its own history, culture, and legacy that show its unique characters. As an oldest, largest, and one of the most advanced institute in marine sciences in China, the Institute of Oceanology, Chinese Academy of Sciences (IOCAS) was established by her founders in 1950 and cherished by her successors ever since. IOCAS has undertaken her own development roadmap over the last seventy years. Many people know its history, achievements, and contributions in marine sciences, but few would know the stories behind the success. This paper intends to reveal the driven factors pushing the institute forward in the past, present, and future.
\end{abstract}

Keyword: mariculture; ocean health; deep sea; Institute of Oceanology, Chinese Academy of Sciences (IOCAS)

\section{INTRODUCTION}

The Institute of Oceanology, Chinese Academy of Sciences (IOCAS) is a multidiscipline institute specialized in marine sciences. IOCAS announced her establishment in 1950, and the current year, 2020, is her 70-year anniversary. Bearing the motto of "Farming the Sea, Exploring the Ocean", it ranks the oldest and largest institute in marine sciences of China. IOCAS features special characters: though not serving as a fishery institute, it has initiated mariculture in China and made it to be a huge industry; though not being a government agent, it has built a long-term observing system along the coast of China seas and in the western Pacific Ocean; though not being a university, it has established the earliest education system for postgraduate student in marine sciences in China, and now it has carried out the first integrated science and education system: Qingdao Science and Education Park (QSEP), Chinese Academy of Sciences (CAS). IOCAS and other 13 marinesciences-related institutes are working together toward the establishment of a scientific research consortium in marine sciences. The College of Marine
Science will also be established in the park in affiliation to the University of Chinese Academy of Sciences (UCAS), and it will house the Center for Ocean Mega-Science of Chinese Academy of Sciences (COMS-CAS). The park will be the new campus for IOCAS and the College of Marine Science, UCAS. The park occupies 133-ha land and $260000-\mathrm{m}^{2}$ construction area, and was contributed by the local government. IOCAS had equipped the first research vessel in 1957 and has built the most advanced research vessel in 2012, which is the only research vessel that belong to the "major national science and technology infrastructure" in the present. The fleet of IOCAS includes 5 different types of research vessels. A modern wharf, together with a deep-sea equipment-development center, was put into use in 2017, and it was also contributed by the local government. The scientific museum of IOCAS is the largest one of the sort in China and one of the largest in the world, for storing over 800000 specimens,

\footnotetext{
* Supported by the Taishan Scholars Project

** Corresponding author: sunsong@qdio.ac.cn
} 


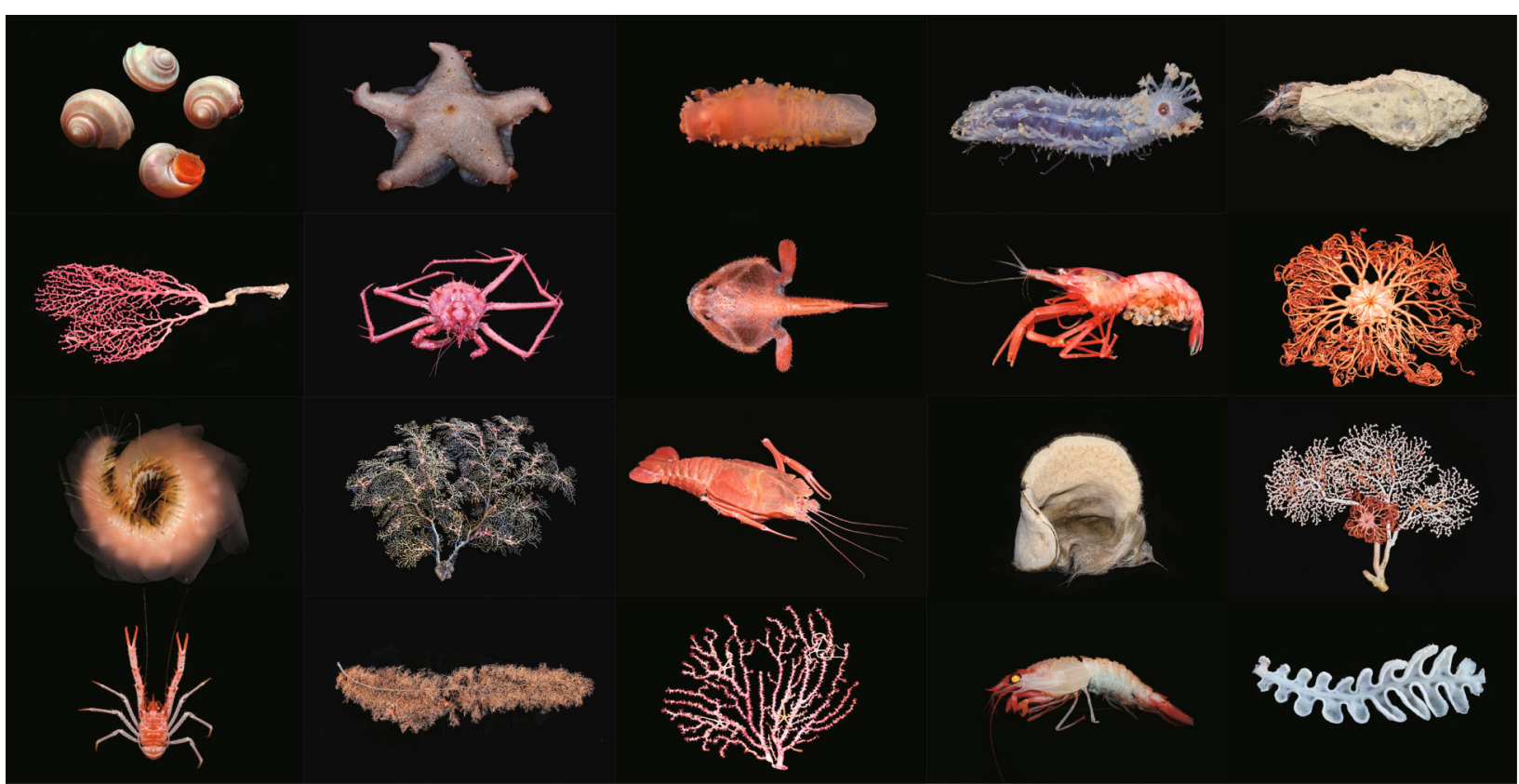

Fig.1 Samples collected in deep sea in the Marine Biological Museum of IOCAS Photo by WANG Shaoqing, IOCAS.

among them 20000 species were identified, which is $1 / 6$ of the total identified species of marine life in the world. The scientific-purpose aquarium in IOCAS is the first and largest facilities for experimental biology and mariculture in China. IOCAS is a governmentaffiliated institution, more than half of the funds come from competitive project, which encourages the employees to "do the right things and keep in the right direction". Therefore, what is the driven factor in the back of the institute? The answer is: the spirit of "to be the best".

\section{BUILDING A SOLID BASIS}

In 1949, Prof. T. C. TUNG and Prof. C. K. TSENG proposed to the preparatory committee for the Chinese Academy of Sciences that CAS should include marine sciences; and this proposal was approved later. The first institution in marine sciences in China was founded in August 1950. Profs. TUNG and TSENG were the first and second director of IOCAS until 1984. As the founders of the IOCAS, they took the development of marine sciences as their responsibility and duty. It is not only for the directors, but for most of the employees in IOCAS have the same sense. Thus, the institute developed from a marine biological laboratory in 1950 to a multidiscipline institute in marine sciences in 1959.

In 1970s, marine taxonomy became very difficult, and funding were short in China as well as abroad.
Many taxonomists were forced to give up their research and turned to other career directions. In such difficult situation, many scientists in IOCAS insisted in marine taxonomy. They believed that taxonomy is very important to marine sciences and the country. With the great efforts made by those scientists, the taxonomy research in IOCAS was able to be pass on and prosper for the last 70 years. The Marine Biological Museum of IOCAS is the largest marine scientific museum in China and one of the most important in the world, which stored a large amount of collections from the coast to the open sea including the polar region and the deep sea (Fig.1). It carried out a big engineering project to have all the collections digitalized and integrated with the environmental conditions when the specimens were collected; now it became a big database. Using this database, scientists could access information about what happed in the last 60 years in the Chinese coastal area, including species composition and biomass variation of fish, shrimp, shellfish, benthos and macroalgae etc., to find out the relationship between these variation and the climate change and human activities. At present, the "ocean health and sustainable development" is the frontal area in marine sciences, not only for marine biology research, but for the entire basic research, including physical oceanography, chemical oceanography, and marine geology, facing the same situation. That is one of the reasons why IOCAS could acquire so many research funds and many important basic research projects. 


\section{TO MEET THE NEED OF THE SOCIETY}

China is a big country, food and protein is very important for Chinese to live well without hunger and poverty. Prof. C. K. TSENG, former director of IOCAS, suggested that the basic research and applied research should be carried out simultaneously. We should develop mariculture to contribute and help our country to solve food problem. It was very difficult for IOCAS to develop mariculture at the beginning, since the scientific basis was very weak. The kelp Saccharina japonica, which was one of the main species for aquaculture, was not a native species but originated from Japan, and must fit the Chinese seawater environment for economic purposes. Another species of economic macroalga was Porphyra yezoensis (now have been renamed to Pyropia yezonesis), which is also called laver. There were very little information about its life cycle and other basic knowledge of this alga. Therefore, Prof. TSENG and his team successfully solved all the basic problems, and made successfully the algae culture a huge national industry, marking the "first wave" of aquaculture in China. At the same time, scientists of IOCAS carried out the life cycle research of Penaeus chinensis, a very valuable species of shrimp, and they obtained the first larvae of the species in laboratory. However, from laboratory experiment to the field application in sea farm, there were a lot of problems to be solved in the aspects of biology, chemistry, physical environment, and physiology and biochemistry etc. Scientists of different disciplines cooperated with each other and solved all the problems, boosted the high-profit industry quickly, which marked the "second wave" of aquaculture in China. Prof. ZHANG Fusui introduced a species of scallop from USA, which made the "third wave" in aquaculture in China. From basic to industry in the development of aquaculture, it improved the life of fisherman, it also partly answered the question of "who can feed Chinese".

In the last 20 years, marine ecosystem safety became a big global issue. As a developing country, China developed the economy very quickly, during which marine environment was greatly affected by human activities and climate change, which is a big challenge in marine sciences. Ocean health and sustainable development has to become our main research direction for a long time ahead, and now it is one of the goals of sustainable development of the United Nations Decade of Ocean Science. IOCAS takes the leadership in ecological disasters research in China, including the harmful algal bloom, green algal bloom, and jellyfish bloom (Stone, 2010; Qiu, 2014). For the ecosystem long-term variation research, IOCAS established an ocean observing system along the coastal area and has a 35-year-old ecological research station in the Jiaozhou Bay, the oldest and comprehensive marine ecological research station in China.

The low latitude western Pacific Ocean plays an important role in the global climate change. From late 1980s, IOCAS joined the Tropical Ocean-Global Atmosphere (TOGA)-Coupled Ocean Atmosphere Response Experiment (TOGA-COARE) project, the research vessel Kexue (Science in Chinese) No.1 began her cruises in the Western Pacific Ocean, which was one of the earliest international cooperative researches for the air-sea interaction research in China. IOCAS proposed and organized the Northwestern Pacific Ocean Circulation and Climate Experiment (NPOCE) program (Fig.2), a multinational and multi-institutional program, and designed to observe, simulate, and understand the dynamics of the Northwestern Pacific (NWP) ocean circulation and its role in low-frequency modulations of regional and global climate, including the western Pacific warm pool variability, the Indonesian Throughflow (ITF) variability, El Niño Southern Oscillation (ENSO), the East Asian Monsoon (EAM), and the NWP cyclones (http://www.npoce.org.cn). IOCAS is one of the main contributors to NPOCE program and built the biggest deep-sea mooring observing system in the western Pacific Ocean.

\section{GO TO THE DEEP SEA}

Ten years ago, when IOCAS celebrated her the $60^{\text {th }}$ anniversary in 2010, a famous senior oceanographer was invited to give a speech, in which he pointed out that IOCAS had a great achievements and took the leadership in the continental shelf research, and he hoped and wondered whether IOCAS could continue to be a flagship in the deep-sea research. It was a dream for scientists and engineers to go to the deep sea for several generations. It was very difficult to carry out the plan, because it requires large equipment such as multifunctional research vessel, deep-sea submersible vehicles, and a series of observing and sampling tools, and none of the above were available in China at that time. To build a deep-sea research system thus became the strategy of IOCAS. 


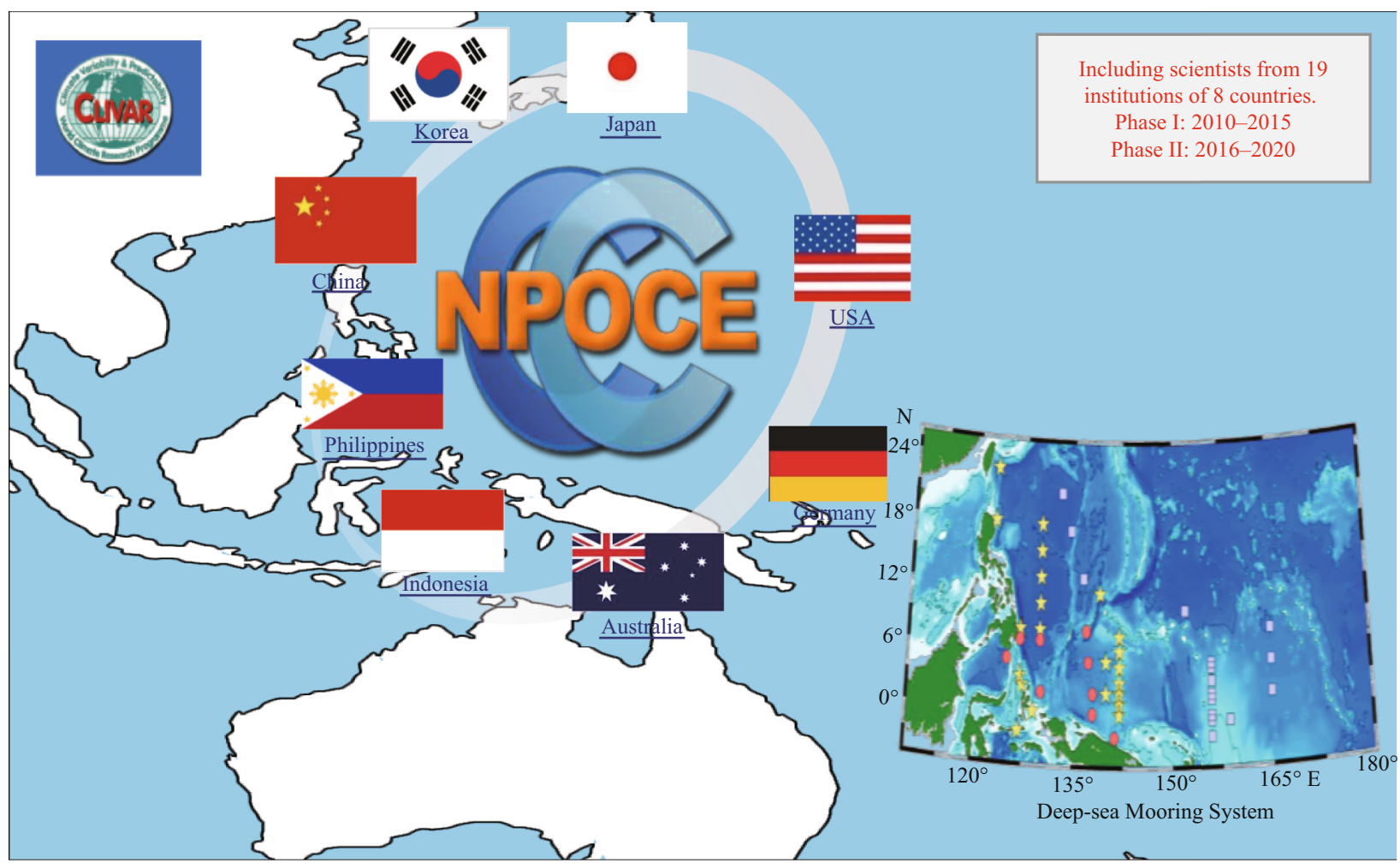

Fig.2 The coverage of the Northwestern Pacific Ocean Circulation \& Climate Experiment (NPOCE) program

\subsection{Built the "flagship" for deep-sea research}

Since the middle of 1980 s, IOCAS people had been trying to build a modern research vessel to meet the need of marine sciences development, but it was not successful until 2007 when the application of a new research vessel was finally approved by the central government. It was one of the 10 "Major National Science and Technology Infrastructure Project" and the only one in marine sciences in China. It took five years since then to finalize the design after extensive debating and competition with many other domestic institutes and universities in marine sciences. It was not just a multipurpose research vessel, but an indicator to that who was capable to take the leadership in the deep-sea research in China (Qiu, 2011). The new research vessel named Kexue (Science in Chinese) (Fig.3) was equipped with 4500 remotely operated vehicle (ROV) and the most update equipment for deep-sea research. R/V Kexue was delivered at the end of 2012, making China capable for the deep-sea research as commented by Nature (Tollefson, 2014). After R/V Kexue, several other new research vessels were built in China, and two of them were the replica of R/V Kexue. Among them, only the first one belong to the "Major National Science and Technology Infrastructure", which means that she is lifetime guaranteed for national financial support for maintenance and upgrading of her equipment.

R/V Kexue started her official debut in 2013, for which the Qingdao municipal government offered a ferry port to IOCAS as the scientific research vessel port, which marked the end of no-port history for the research vessel fleet of IOCAS. This port was rebuilt and upgraded from a civil ferry port to an integrate research center of marine investigation, including berths for research vessels, a warehouse building for equipment and instrument, and a physical center for construction and maintenance of the large equipment (such as ROV etc.) (Fig.4).

\subsection{Systematic research in western Pacific Ocean}

From 2013-2018, IOCAS carried out "Western Pacific Ocean System (WPOS): Structure, Dynamics and Consequences" project, it was one of the 10 "Strategic Priority Research Program of Chinese Academy of Sciences" at that time. The 5-year budget was 1.1 billion RMB; and more than 700 scientist from 29 institutes or universities joined the project, about half of them came from IOCAS. R/V Кехие serves as the main research vessel, together with other four smaller ones. The goal of this project was 


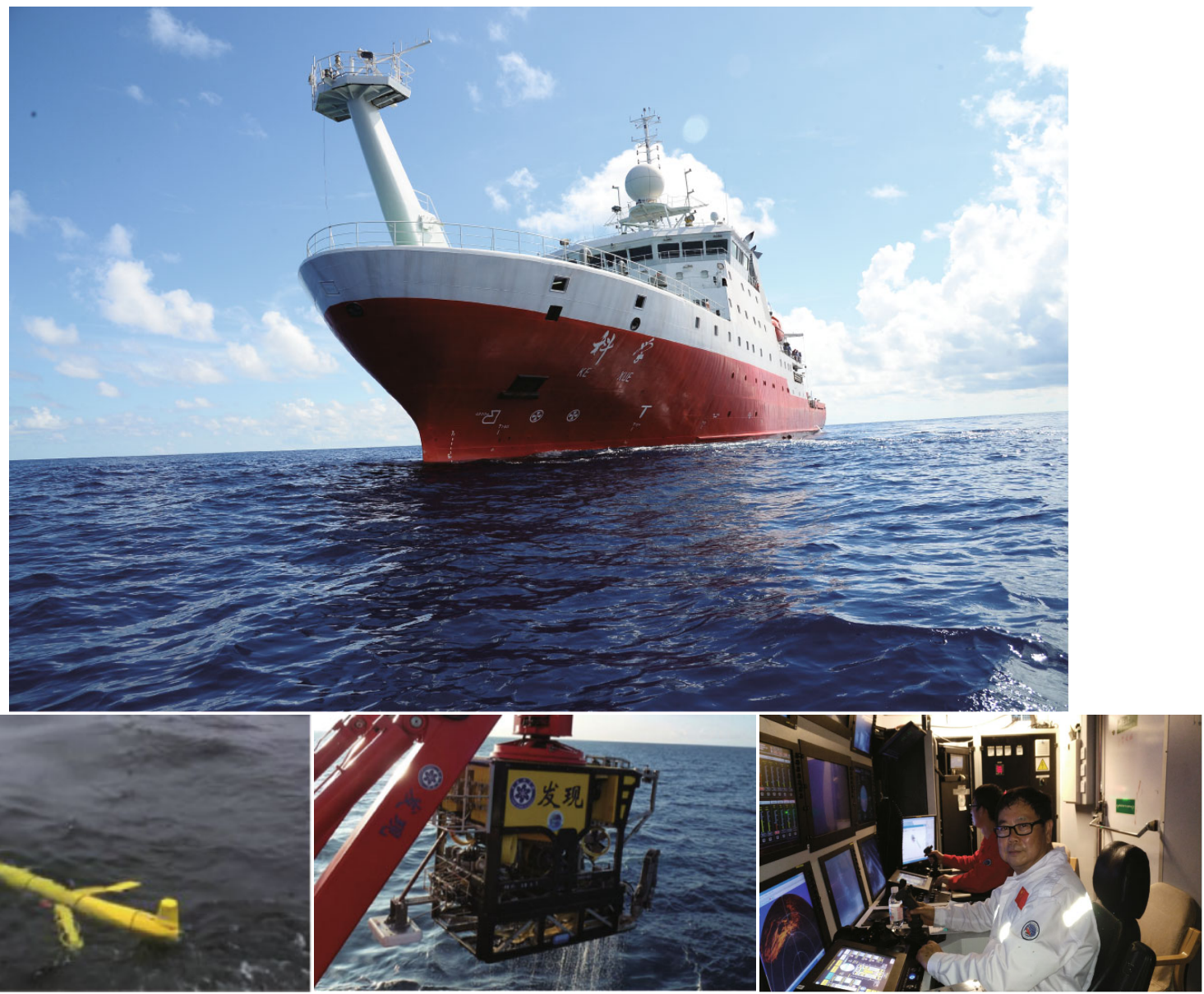

Fig.3 R/V Kexue (upper-panel) and other mounted facilities (lower panel)— the platform for the deep-sea research

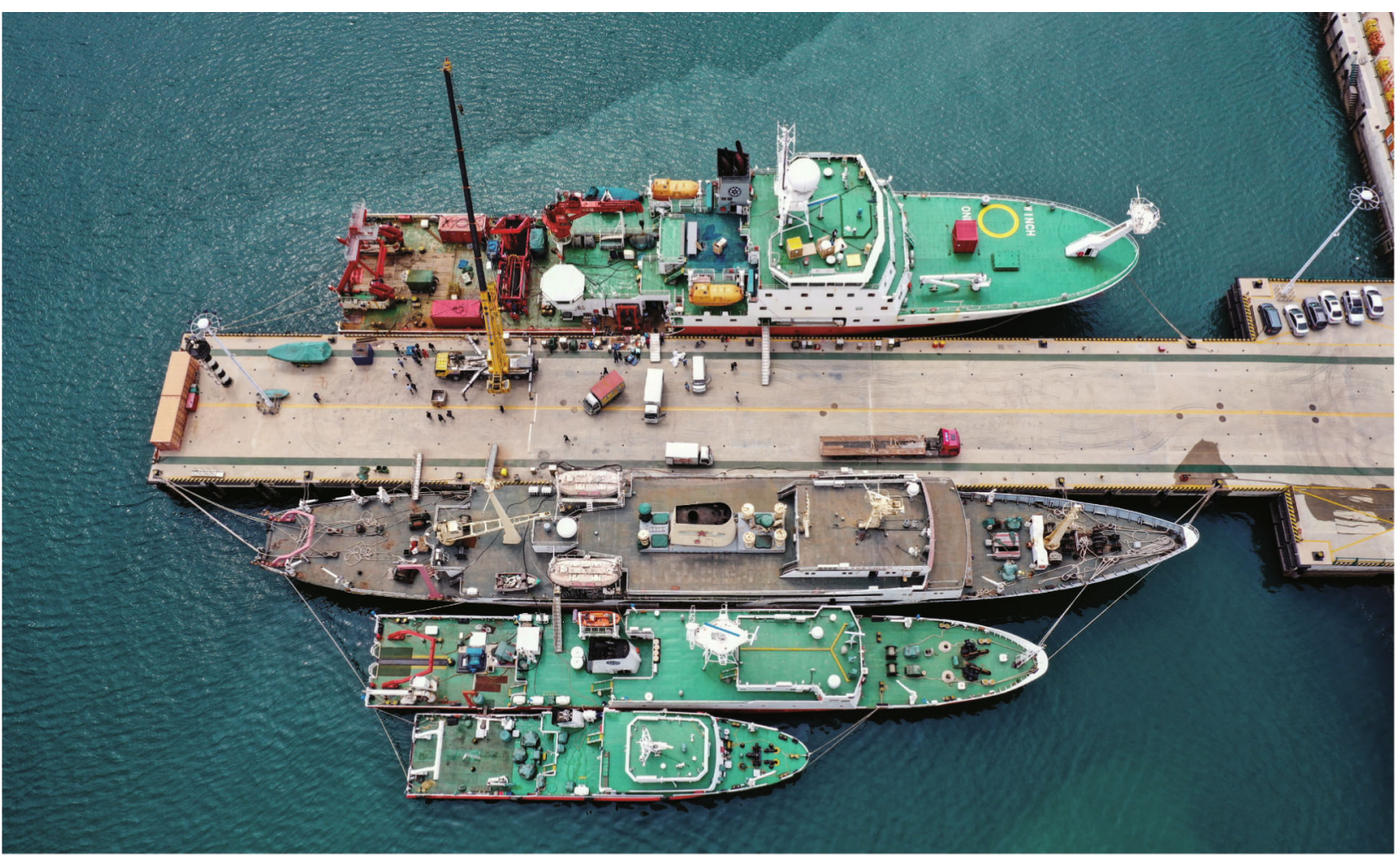

Fig.4 Four research vessels harbored at the pier of IOCAS 


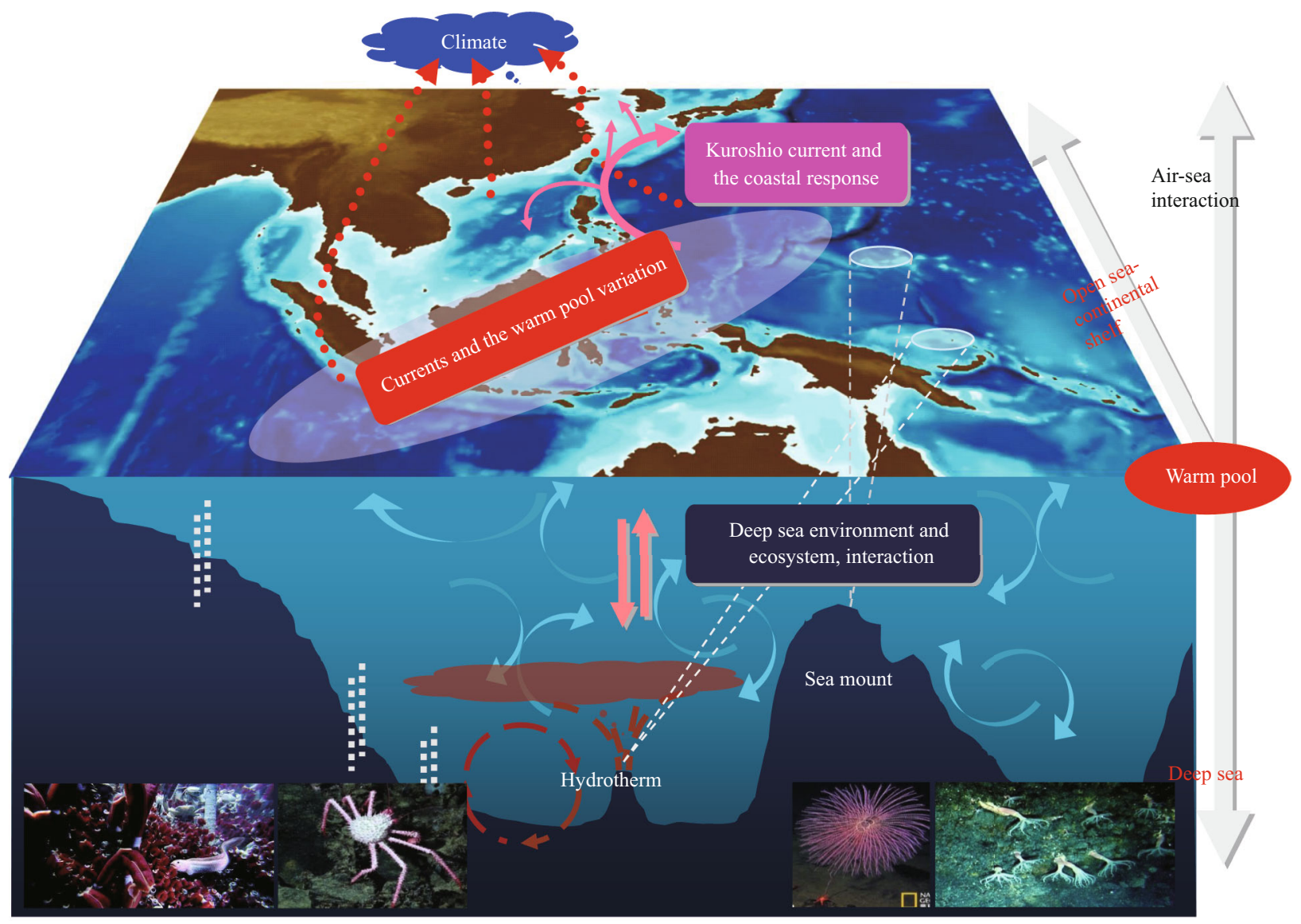

Fig.5 Diagram of the main research directions of the WPOS project

to understand the variation and consequence of ocean current system in the western Pacific, and the impact on the East Asia climate and Chinese coastal ecosystem, exploring the deep-sea environment and ecosystem. It was the first time to have such big project in marine sciences in China, and it was also the first time to study the ocean systematically. There were four core tasks for this project: (1) the Western Pacific Ocean deep sea currents variation and its influence to the ENSO and monsoon etc.; (2) Kuroshio variation and its impact on Chinese coastal ecosystem; (3) deep-sea research, including hydrothermal fluid, cold seep and seamount etc.; and (4) facilities and instruments needed in the deep-sea research, such as autonomous underwater vehicle (AUV), ROV, observing and sampling tools etc.

The WPOS project aimed at air-sea interaction, affection of Kuroshio current to coastal ecosystem, deep-sea environment, and lives in the deep sea. Many young scientists and engineers were trained and brought up in the process of the project. Within five years, 35 deep-sea cruises and 113 coastal cruises were carried out in 330000 nautical miles in distance, the ROV dived for 210 times; more than 5000 samples and more than 600 species were collected; 1198 Science Citation Index (SCI)-papers were published including two in Nature, one in Science and one in Proceedings of the National Academy of Sciences of the United States of America (PNAS), and in addition, 15 books were published. Most importantly, this project has made our research directions clear (Figs.5-8): multi-sphere interaction in the deep sea, ocean health and sustainable development, and marine life science. It was the milestone of IOCAS from coastal to the deep sea (Tollefson, 2014).

\section{FOR THE FUTURE}

The ocean research plays a vital role in economic development with great potentials in fishery, medicine, and health productions. Natural resources of minerals and fossil energies in the deep sea have great significance to the economy development. At the same time, all these industry activities may have impacts on the environment and degenerate the health of marine ecosystem. A healthy and sustainable ocean is essential for the societies at present and in the 


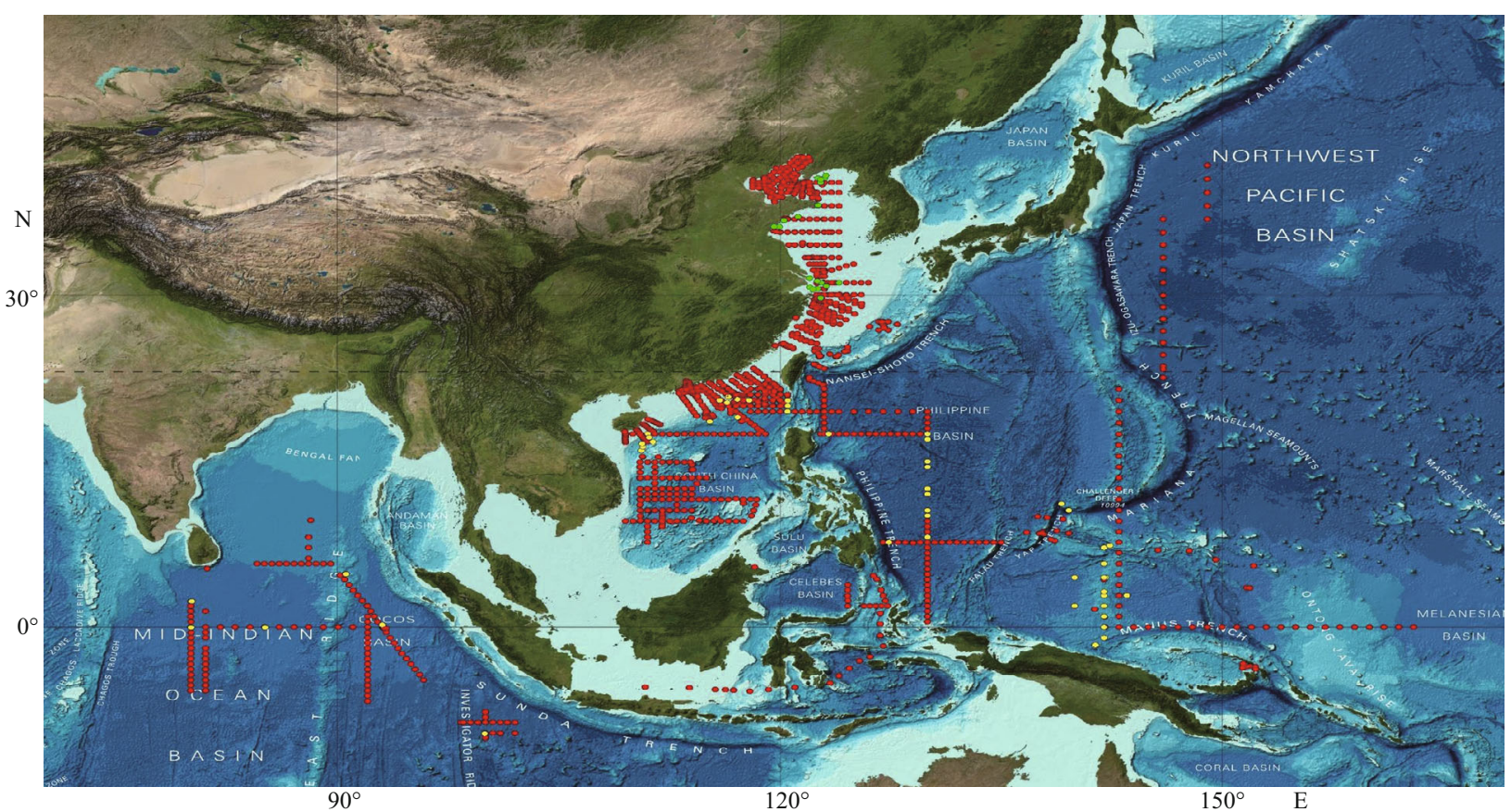

Fig.6 Sketch map of the research area and investigation stations of the WPOS project

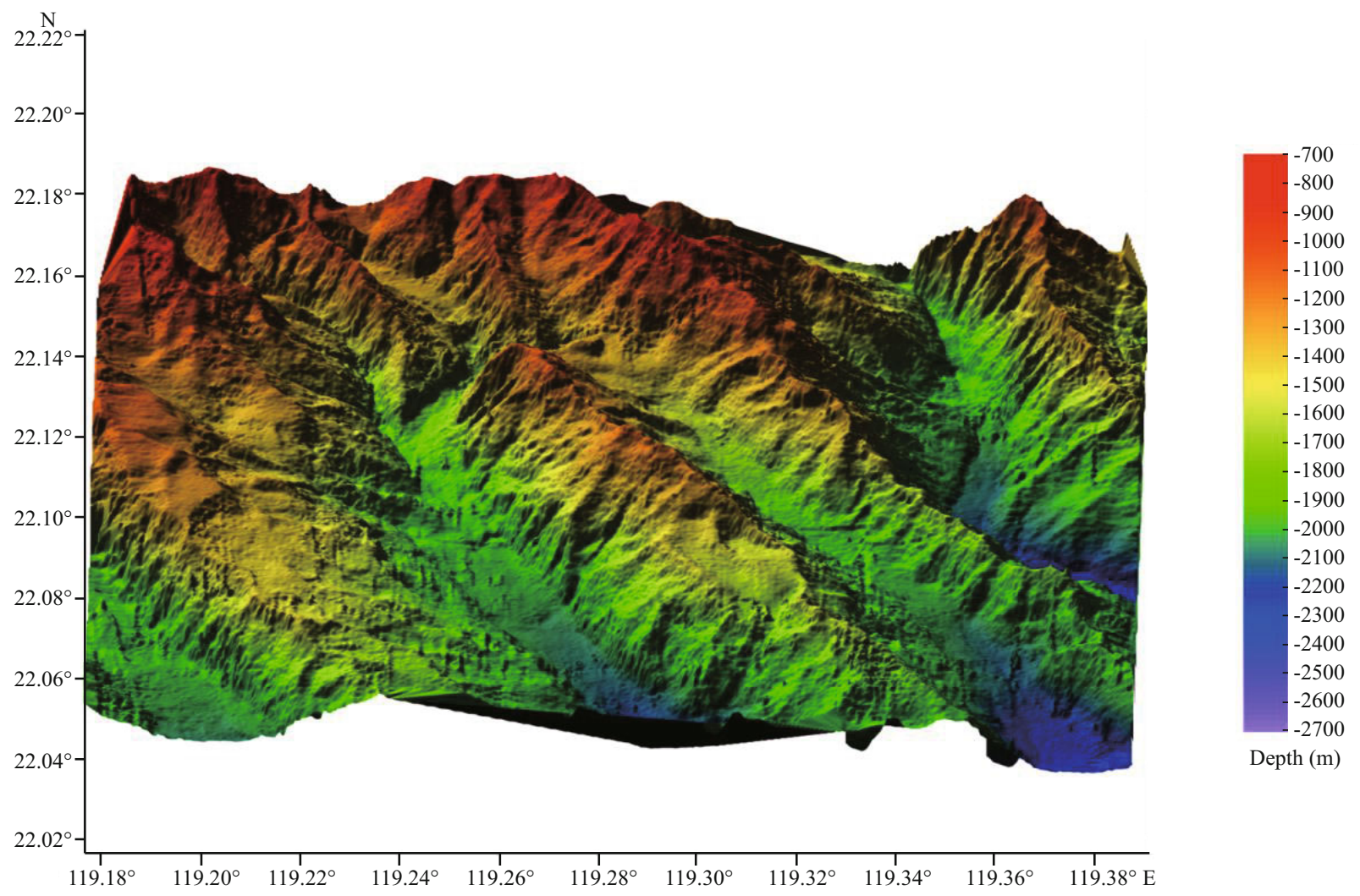

Fig.7 The first geophysical map acquired in the first deep-sea cruise by R/V Kexue in 2014

future. Both of the exploration and protection techniques are required urgently, not only for the central government, but the companies and local governments, presenting a new challenge and opportunity for marine sciences and technology. How to manage to meet the need of the economy and society is a big issue for us. Any single institute or university is unable to carry out such a systematic program; however, cooperation among them is the right way. Marine sciences and technology demands 


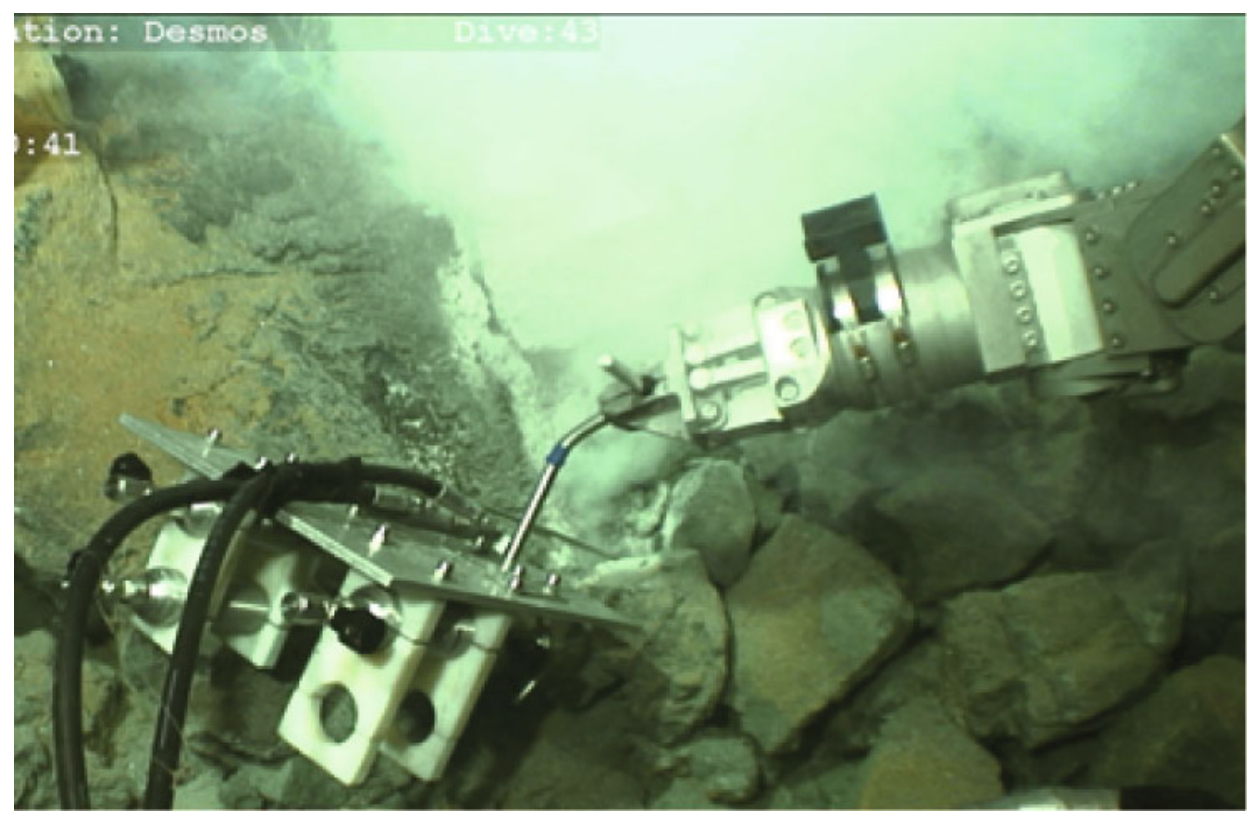

Fig.8 Hydrothermal fluid experiment in the deep sea

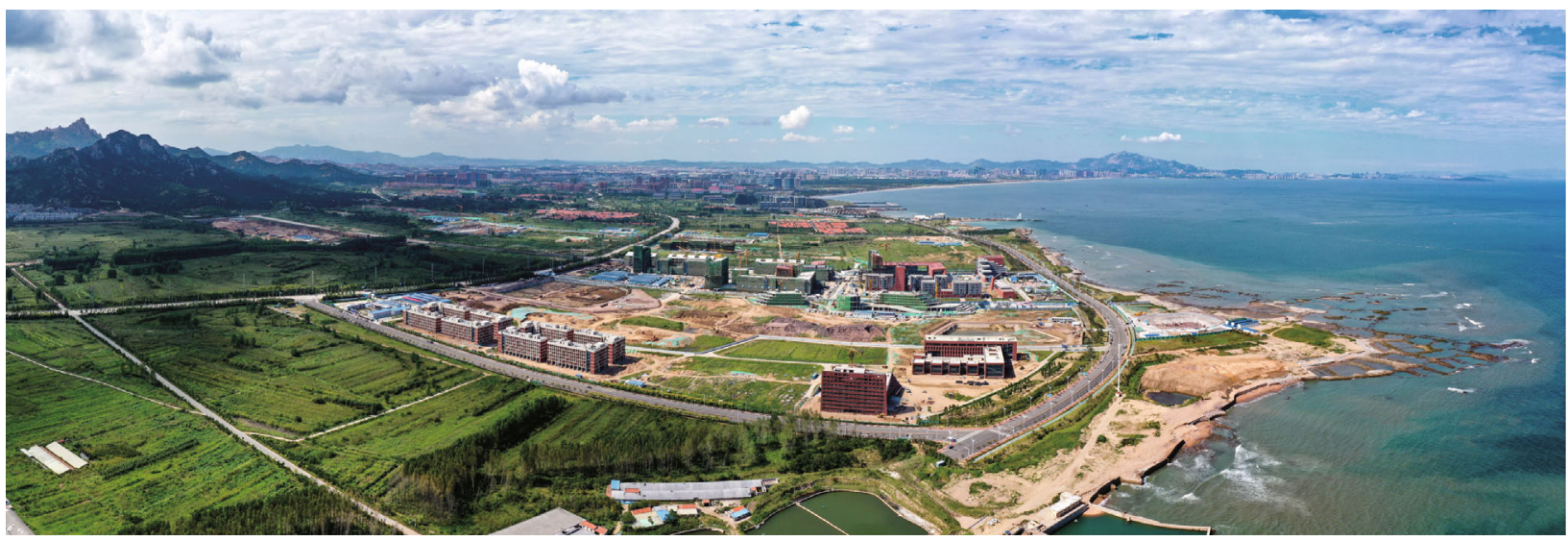

Fig.9 The Qingdao Science and Education Park, CAS, to be inaugurated in 2021

for many updated large facilities, which costs a fortune from manufacture to maintenance, and only a few institutions can afford it. Therefore, we shall share the large facilities properly. For the growing demand from exploring resources in the ocean and protecting the environment, we would need new materials, new technology, new methods, and new ideas. Therefore, we must invite and cooperate with the institutions outside of traditional marine institutions, establish a close relationship with companies and local governments for the transition from scientific research outcome to the industry, economy, and society. Most importantly, we need more qualified young scientists, engineers, and managers in the fields of marine sciences, technology, and blue economy, which calls for a new type of education model urgently. In 2016, Chinese Academy of Sciences and Qingdao municipal government signed a strategic agreement to co-build the Qingdao Science and Education Park, Chinese Academy of Sciences (Fig.9). It will be an integrated system, including a cluster of laboratories for marine sciences and technology, large equipment for deep sea research and exploitation, an integrated postgraduate school (College of Marine Science, University of Chinese Academy of Sciences), a joint center for industry, research, technology, and education. The park will act as a bridge to link research, education, and the blue economy. The Qingdao municipal government provided 133-ha land and constructed $260000 \mathrm{~m}^{2}$ floor area in the first construction phase, with an investment of 2.5 billion RMB, and CAS will organize 13 marine sciences related institutions to establish the Center for Ocean Mega-Science, Chinese Academy 
of Sciences (COMS-CAS). At present, the first construction phase has been almost finished and will put into use in 2021, and the integrated graduate school will begin as a branch campus of UCAS. In addition, the COMS has been approved by CAS, and IOCAS is the leader and organizer of COMS in cooperation with other 12 CAS institutes.

\section{CONCLUDING REMARKS}

On the occasion of the $70^{\text {th }}$ anniversary of IOCAS, the review of her development process will help us understand the driven factors of her glorious history, scientific ideas, and methods, and perceive what determined our research direction and activities. Every institution has its own mission and developmental philosophy, and they may be mission oriented, funding oriented or research-paper oriented. What about IOCAS and her people? They are such a group of people who are responsible for the development of marine sciences and technology, trying their best to meet the national needs from the society and economy, and navigate the great research ship towards deep-blue ocean, and pioneer the frontier of the marine sciences and technology in China. This is the past, present, and future of IOCAS, and what we did, what we are doing, and what we will do in the future.

\section{DATA AVAILABILITY STATEMENT}

The datasets generated and/or analyzed during the current study are available from the corresponding author on reasonable request.

\section{References}

Qiu J. 2011. China pushes to rule the waves. Nature, 480: 165, https://doi.org/10.1038/4800165a.

Qiu J. 2014. Coastal havoc boosts jellies. Nature, 514: 545, https://doi.org/10.1038/514545a.

Stone R. 2010. Chinese initiative aims to comprehend and combat a slimy foe. Science, 330(6010): 1 464-1 465, https://doi.org/10.1126/science.330.6010.1464.

Tollefson J. 2014. China plunges into ocean research. Nature, 506: 276, https://doi.org/10.1038/506276a. 